\title{
Crystallization Behaviour of Electroless Ni-P UBM with Medium Phosphorous Induced by Single and Step Heat Treatment
}

\author{
Han-Byul Kang ${ }^{1,2}$, Jongwoo Park ${ }^{2}$, Jee-Hwan Bae ${ }^{1}$ and Cheol-Woong Yang ${ }^{1, *}$ \\ ${ }^{1}$ School of Adv. Material Sci. \& Eng., Sungkyunkwan University, Suwon 440-746, Korea \\ ${ }^{2}$ Technology Reliability, System LSI, Samsung Electronics, Yongin 446-711, Korea
}

\begin{abstract}
This study examined the crystallization behavior of electroless Ni-P UBM with an medium phosphorous content $(\sim 15$ at $\%)$ induced by a single and step heat treatment using in-situ transmission electron microscopy (TEM). Different heat treatment processes affected the crystallization behavior of electroless Ni-P UBM. After single heat treatment at $300^{\circ} \mathrm{C}$ for $60 \mathrm{~min}$, the electroless Ni-P UBM contained Ni and $\mathrm{Ni}_{3} \mathrm{P}$. In addition to $\mathrm{Ni}$ and $\mathrm{Ni}_{3} \mathrm{P}$, more complex Ni-P compounds, such as $\mathrm{Ni}_{12} \mathrm{P}_{5}$ and $\mathrm{Ni}_{5} \mathrm{P}_{2}$ formed in the electroless Ni-P UBM resulting from a step heat treatment at $150^{\circ} \mathrm{C}$ for $60 \mathrm{~min}$ followed by $300^{\circ} \mathrm{C}$ for $60 \mathrm{~min}$. [doi: $10.2320 / \mathrm{matertrans} . \mathrm{M} 2010178$ ]
\end{abstract}

(Received May 20, 2010; Accepted July 5, 2010; Published August 19, 2010)

Keywords: under bump metallization, electroless nickel-phosphorous, in-situ transmission electron microscopy (TEM)

\section{Introduction}

In flip chip interconnections using a solder bump, under bump metallization (UBM) is desirable because the solder cannot be bonded directly to the $\mathrm{Al}$ or $\mathrm{Cu}$ pads. Therefore, electroless Ni-P (EN-P) UBM has attracted considerable attention for flip chip bumping technology on account of its simple process, low cost, good solder wettability, bump uniformity and superior diffusion barrier performance. ${ }^{1-5)}$

EN-P films can be classified into three categories with respect to the microstructural differences as a function of the phosphorus content; phosphorus supersaturated structure with a low phosphorous content $(<7$ at $\%)$, compounded nanocrystalline $\mathrm{Ni}$ and amorphous structure with a medium phosphorous content $(8 \sim 19$ at $\%)$, and fully amorphous structure with a high phosphorous content $\left(>20\right.$ at\%). ${ }^{6-9)}$ the thermo-mechanical and/or physical properties of EN-P UBM depend on the microstructural characteristics, which are governed and determined by the crystallization behavior during post heat treatment, such as the reflow and aging process. It was reported that the formation of crystalline Ni-P phases is quite sensitive to the heat treatment, and their mechanical properties can be reversed when exposed to an overheating temperature and improper dwelling time. ${ }^{10,11)}$ Therefore, it is important to understand the crystallization behavior of EN-P UBM as a function of the heat treatment and profile. Many studies characterized the crystallization behavior of EN-P films with different phosphorous contents under a single heat treatment. ${ }^{12-18)}$ However, few studies are available. Moreover, the effects of the post heat profile, e.g. a single and step heat treatment, on the crystallization behavior of EN-P films with respect to the phosphorous content are not completely understood. Therefore, a systematic well characterized physical study is essential for understanding the crystallization behavior of EN-P UBM.

This study examined the crystallization behavior of the amorphous EN-P UBM with a medium phosphorous content (15 at\%) as a function of the heat profile consisting of a single $\left(300^{\circ} \mathrm{C} / 60 \mathrm{~min}\right)$ and $\operatorname{step}\left(150^{\circ} \mathrm{C} / 60 \mathrm{~min}\right.$ followed by $300^{\circ} \mathrm{C} /$

*Corresponding author, E-mail: cwyang@skku.edu

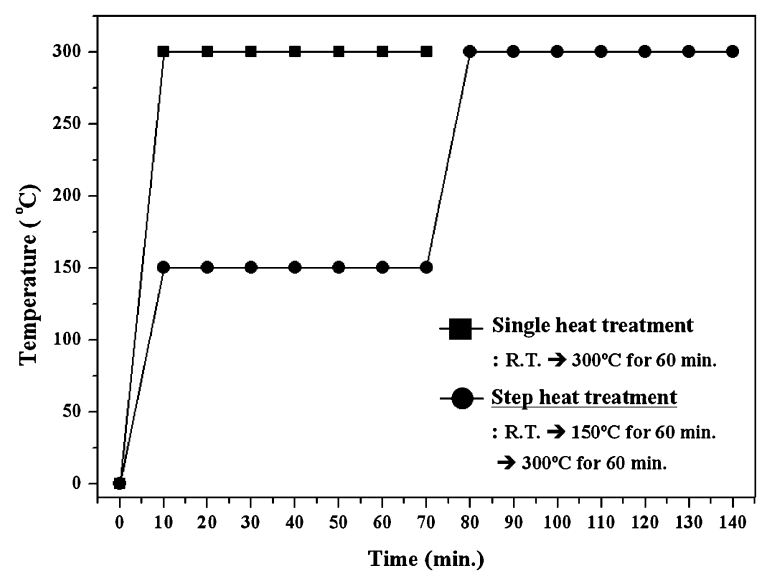

Fig. 1 Heat profile of a single and step heat treatment.

$60 \mathrm{~min}$ ) heat treatment. One of the aims was to characterize the crystallization behavior of EN-P with a medium phosphorous content using in-situ transmission electron microscopy (TEM), which can provide a better understanding of the microstructural behavior and the mechanism evolved.

\section{Experimental Procedure}

Copper foil was used as the substrate in EN-P plating. A commercially available EN-P plating solution (ICP Nicoron GIB series, Okuno Chemical Industries Co., Ltd., Japan) was used for EN-P plating. The EN-P plated layer with a $\sim 15$ at $\%$ phosphorous content was processed at $90^{\circ} \mathrm{C}$ for $30 \mathrm{~min}$. After plating, the sample was heat treated in a tube furnace with an argon atmosphere. Figure 1 shows the temperature profile of a single $\left(300^{\circ} \mathrm{C} / 60 \mathrm{~min}\right)$ and step $\left(150^{\circ} \mathrm{C} / 60 \mathrm{~min}\right.$ followed by $300^{\circ} \mathrm{C} / 60 \mathrm{~min}$ ) heat treatment. The microstructure of EN-P UBM as-plated and after heat treatment was analyzed by Xray diffraction (XRD, Rigaku, Japan) and TEM. The XRD patterns of the sample after the heating processes were recorded at room temperatures. The TEM samples were prepared using an ultramicrotome (RMC MT 7000) and characterized by high resolution (HR)-TEM (JEM-2100F, 


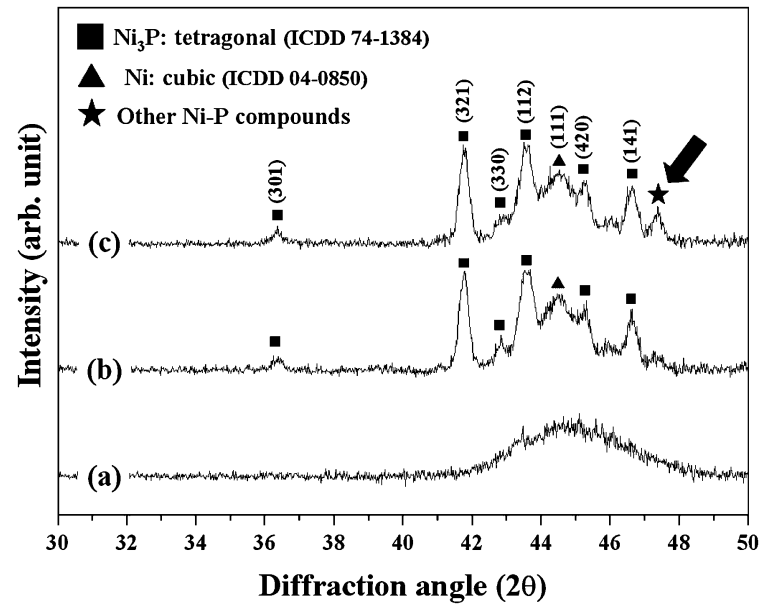

Fig. 2 XRD patterns of the as-plated EN-P and heat-treated films: (a) asplated ENP UBM, (b) a single heat treatment $\left(300^{\circ} \mathrm{C} / 60 \mathrm{~min}\right)$ and (c) a step heat treatment $\left(150^{\circ} \mathrm{C} / 60 \mathrm{~min}\right.$ followed by $\left.300^{\circ} \mathrm{C} / 60 \mathrm{~min}\right)$.

Jeol Co. Ltd.) equipped with a scanning transmission electron microscope (STEM) and energy dispersive x-ray spectrometer (EDS). A JEOL 3011 TEM equipped with a hot stage was used for the in-situ TEM studies.

\section{Results and Discussion}

\subsection{XRD analysis after single and step heat treatment}

Figure 2 shows XRD patterns of the as-plated EN-P and post heat treated films. As shown in Fig. 2(a), the XRD patterns of the as-plated sample before heat treatment revealed a single broad peak at $45^{\circ} 2 \theta$, which indicates an amorphous structure. Several sharp peaks were observed on the XRD patterns when EN-P UBM was exposed to a single heat treatment at $300^{\circ} \mathrm{C} / 60 \mathrm{~min}$ [see Fig. 2.(b)]. Two crystalline peaks, $\mathrm{Ni}$ and $\mathrm{Ni}_{3} \mathrm{P}$, were noted on the XRD patterns, showing that both $\mathrm{Ni}$ and $\mathrm{Ni}_{3} \mathrm{P}$ form in EN-P UBM during a single heat treatment. Figure 2(c) presents the XRD patterns of a step heat treated EN-P film, $150^{\circ} \mathrm{C} / 60 \mathrm{~min}$ followed by $300^{\circ} \mathrm{C} / 60 \mathrm{~min}$. $\mathrm{Ni}$ and $\mathrm{Ni}_{3} \mathrm{P}$ peaks were observed on the XRD pattern, which is similar to that of the single step heat treated EN-P UBM. In addition, the XRD pattern of the step treated EN-P UBM showed a new sharp peak at $\sim 47.38^{\circ}$ $2 \theta$ corresponding to the $(240) \mathrm{Ni}_{12} \mathrm{P}_{5}\left(46.96^{\circ} 2 \theta\right)$ or $(600)$ $\mathrm{Ni}_{5} \mathrm{P}_{2}\left(47.64^{\circ} 2 \theta\right)$ peak. Various Ni-P compounds can be formed in EN-P UBM with a medium phosphorous, particularly those treated at intermediate temperatures $\left(150^{\circ} \mathrm{C}\right)$ using a step heat profile. It should be noted that a single heat profile at $300^{\circ} \mathrm{C} / 60$ min provides $\mathrm{Ni}$ and $\mathrm{Ni}_{3} \mathrm{P}$ as the main precipitates.

Amorphous EN-P is thermo-dynamically unstable and transforms to more stable structures during heat treatment. Many studies of the crystallization behavior of EN-P films reported that crystallized Ni-P phases are sensitive to the phosphorus content in the EN-P film. ${ }^{9,12-16)}$ In the case of a low ( $<7 \sim 9$ at $\%)$ and medium ( $\sim 18$ at $\%)$ phosphorous content, the Ni-P compound precipitate is dominated by $\mathrm{Ni}_{3} \mathrm{P}^{6,16,18)}$ However, at high phosphorous contents ( $>20$ at $\%$ ), $\mathrm{Ni}_{3} \mathrm{P}$ and $\mathrm{Ni}_{\mathrm{x}} \mathrm{P}_{\mathrm{y}}$ compounds, such as $\mathrm{Ni}_{2} \mathrm{P}, \mathrm{Ni}_{5} \mathrm{P}_{2}$ and $\mathrm{Ni}_{12} \mathrm{P}_{5}$, form after heat treatment. ${ }^{12,13,16)}$ And the transformation from the amorphous Ni-P to the crystalline equilibrium two-phase mixture of $\mathrm{Ni}$ and $\mathrm{Ni}_{3} \mathrm{P}$ occurred through the crystallization of the intermediate meta-stable mixture of $\mathrm{Ni}_{\mathrm{x}} \mathrm{P}_{\mathrm{y}}$ and $\mathrm{Ni}$ in accordance with the Ostwald rule. ${ }^{19)}$ Surprisingly, the medium phosphorous (15 at\%) in the EN-P UBM processed by a step heat treatment yielded similar results to those observed with a high phosphorous content $(>20$ at $\%$ ) reported in literatures. Therefore, the given heat profile for EN-P UBM plays an important role in the crystallization behavior.

\subsection{In-situ TEM analysis during step heat treatment}

In-situ TEM was employed to determine the reason for the unexpected crystallization behavior of the EN-P with the medium phosphorous (15 at\%) induced by a step heat treatment. Figure 3 shows the in-situ TEM image sequence during heat treatment at an intermediate temperature $\left(150^{\circ} \mathrm{C}\right)$. As shown in the selected area diffraction (SAD) pattern in Fig. 3(a), the as-plated EN-P UBM exhibited diffused halo rings, which suggests an amorphous structure. However, the dark spots become more apparent, and they grow in size with increasing heat treatment duration (see Fig. 3(b) (d)). Given that the dark spots indicate nanocrystalline Ni. Figure 4 shows the results of ex-situ TEM analyses on the EN-P UBM exposed to $150^{\circ} \mathrm{C}$ for $60 \mathrm{~min}$. As shown in the diffraction pattern in Fig. 4(a), the d-spacing measured from the Debye rings apparently represents crystalline $\mathrm{Ni}$. This shows that crystallized $\mathrm{Ni}$ exists in the amorphous EN-P UBM even after heat treatment at $150^{\circ} \mathrm{C}$. Furthermore, Table 1 shows the results of STEM/EDS analyses on the EN-P heat treated at $150^{\circ} \mathrm{C}$ in a step profile. The changes in $\mathrm{Ni}$ and $\mathrm{P}$ are obvious, which is well matched with the in-situ TEM results. The dark area contained $\sim 92$ at $\% \mathrm{Ni}$ and $\sim 8$ at\% $\mathrm{P}$ (position 1 4 in Fig. 4(b)), suggesting that it is $\mathrm{Ni}$ rich. However, the phosphorous content increased up to 23 at\% in positions $5 \sim 8$ shown in Fig. 4(b), this suggests that $\mathrm{P}$ was segregated at the region between the $\mathrm{Ni}$ rich regions, and the $\mathrm{P}$ concentration can increase to more than 15 at\% after heat treatment at intermediate temperatures $\left(150^{\circ} \mathrm{C}\right)$. It was assumed that the change in $\mathrm{Ni}$ and $\mathrm{P}$ composition governed by a step heat treatment can result in a more complicated crystallization behavior of the EN-P UBM with a medium phosphorous content $(\sim 15$ at $\%)$. These results are discussed in the later parts.

Figure 5 shows in-situ TEM images during a step heat treatment at $150^{\circ} \mathrm{C} / 60 \mathrm{~min}$ followed by $300^{\circ} \mathrm{C} / 60 \mathrm{~min}$. As shown in Fig. 5(a), several dark spots $(1 \sim 1.5 \mathrm{~nm})$ were observed on the as-plated EN-P UBM. Since the EN-P film contains $\sim 15$ at $\%$ phosphorous, it is reasonable that the EN-P consists of nanocrystalline Ni and amorphous EN-P, which is consistent with previous studies. ${ }^{13,16,17)}$ In an earlier stage of heat treatment at $150^{\circ} \mathrm{C}$, the dark spots (Ni) became clearer in shape and increased in size with increasing dwelling time (see Fig. 5(b) and (c)). These results are similar to the in-situ TEM analyses shown in Fig. 3. The crystallization of Ni-P compounds was observed as the temperature reached $300^{\circ} \mathrm{C}$. In turn, Ni-P crystallization occurs rapidly after $\sim 100$ seconds. As shown in Fig. 5(f), the diffraction pattern of the EN-P UBM consisted of a Debye ring superimposed with diffraction spots, which supports the crystallized Ni-P 

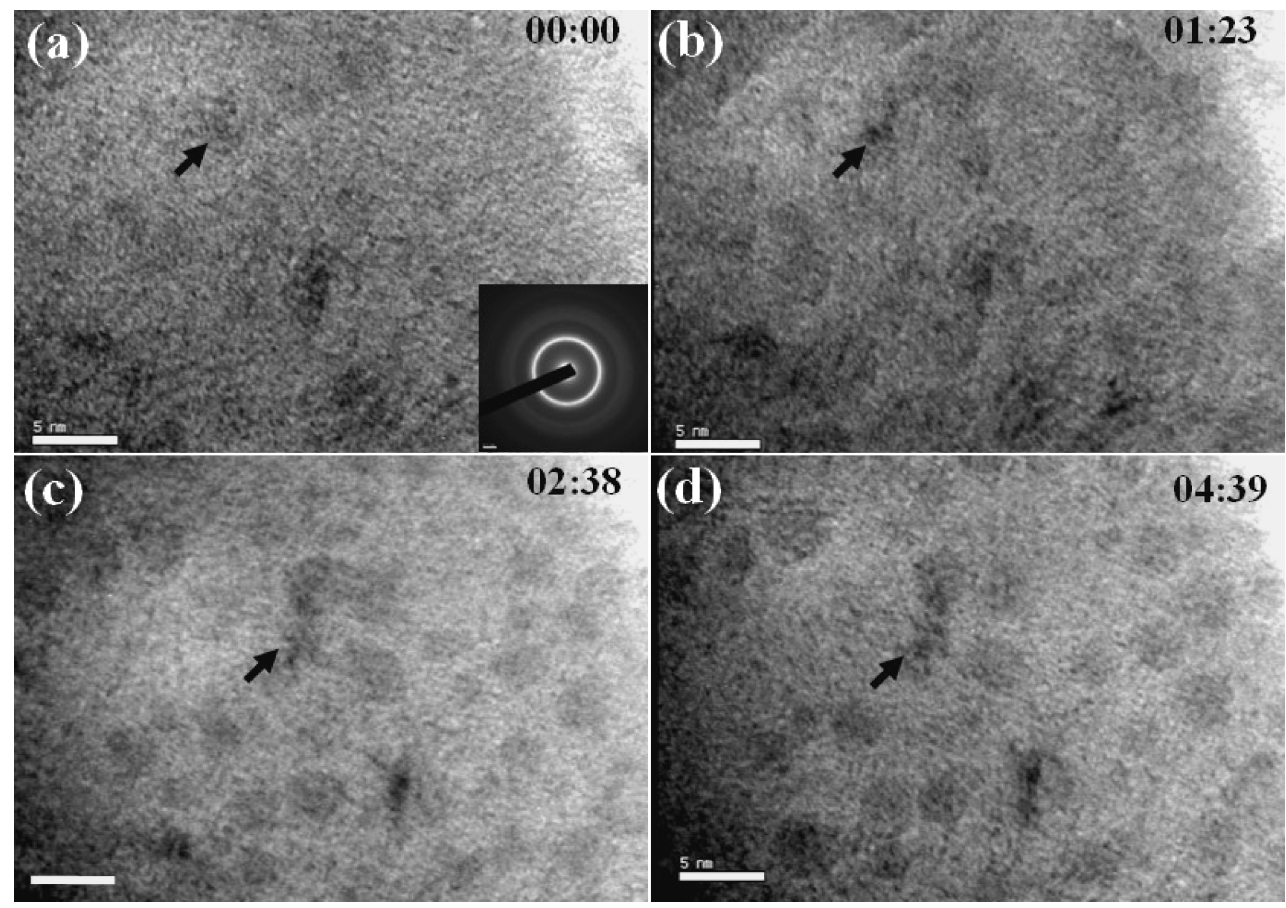

Fig. 3 In-situ TEM images during heat treatment at an intermediate temperature at $150^{\circ} \mathrm{C}$ : As the heat treatment duration increases, dark spots of Ni become more clearly and grows in size with increasing duration (arrows: reference position). The scale bar shown in TEM images is $5 \mathrm{~nm}$.

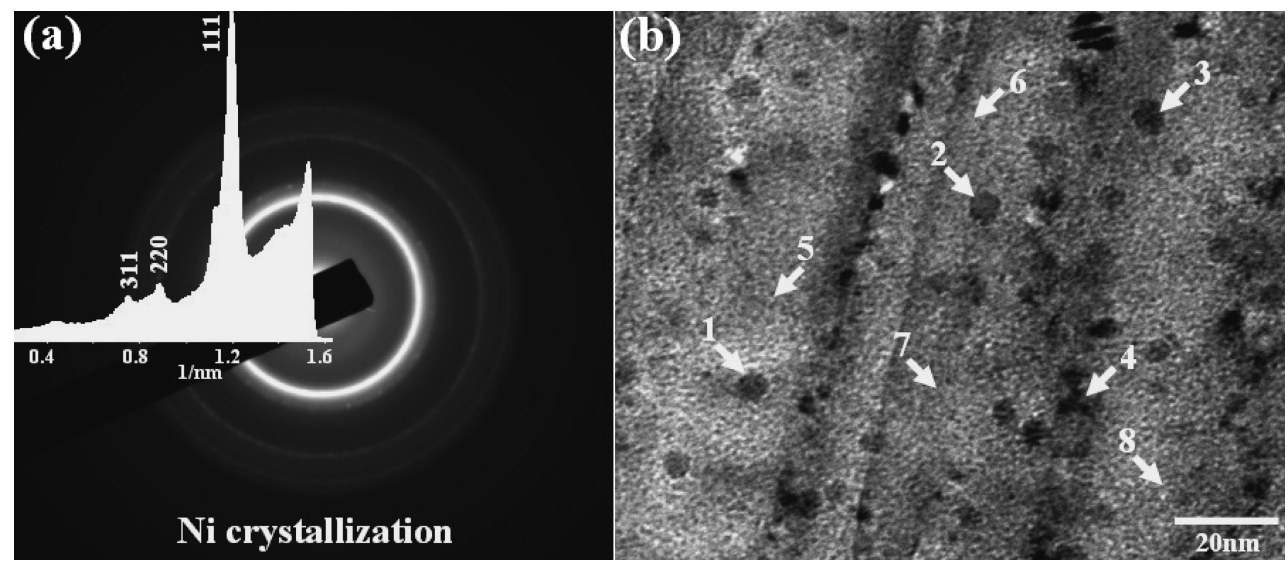

Fig. 4 TEM results of the EN-P UBM after the heat treatment at $150^{\circ} \mathrm{C}$ for $60 \mathrm{~min}$. Note that position $1 \sim 4$ consists of $\sim 92$ at $\%$ Ni and $\sim 8$ at $\%$ P, and position 5 8 indicates phosphorous up to 23 at $\%$.

Table 1 The results of quantitative STEM/EDS analyses on the heat treated EN-P UBM at $150^{\circ} \mathrm{C}$ for $60 \mathrm{~min}$.

\begin{tabular}{ccc}
\hline Position & $\mathrm{Ni}(\mathrm{at} \%)$ & $\mathrm{P}($ at\%) \\
\hline 1 & $91.73 \pm 1.13$ & $18.27 \pm 1.01$ \\
\hline 2 & $92.64 \pm 0.93$ & $17.36 \pm 0.71$ \\
\hline 3 & $92.91 \pm 0.85$ & $17.09 \pm 0.69$ \\
\hline 4 & $92.25 \pm 1.09$ & $17.75 \pm 0.93$ \\
\hline 5 & $76.31 \pm 0.84$ & $23.69 \pm 0.97$ \\
\hline 6 & $76.10 \pm 1.08$ & $23.90 \pm 1.20$ \\
\hline 7 & $75.56 \pm 1.32$ & $24.44 \pm 1.55$ \\
\hline 8 & $76.17 \pm 0.95$ & $23.83 \pm 1.02$ \\
\hline
\end{tabular}

compounds formed in the EN-P UBM. Nano-beam-electrondiffraction (NBED) was used to identify the crystalline phases in the EN-P UBM after a step heat treatment. Figure 6 shows the results of NBED analyses on the samples exposed to a step heat treated EN-P UBM shown in Fig. 5(f). NBED confirmed that crystallized EN-P UBM consisted of a mixture of $\mathrm{Ni}_{3} \mathrm{P}, \mathrm{Ni}_{12} \mathrm{P}_{5}, \mathrm{Ni}_{5} \mathrm{P}_{2}$ and $\mathrm{Ni}$. Figure 6 shows that the indexed NBED patterns of $\mathrm{Ni}_{3} \mathrm{P}, \mathrm{Ni}_{12} \mathrm{P}_{5}, \mathrm{Ni}_{5} \mathrm{P}_{2}$ and $\mathrm{Ni}$ with the zone axis of [101], [112] ], [001] and [011], respectively. Few studies have reported the similar results. Pittermann and Ripper using high energy electron diffraction confirmed the existence of a meta-stable $\mathrm{Ni}_{5} \mathrm{P}_{2}$ or $\mathrm{Ni}_{2.55} \mathrm{P}$ structure prior to the formation of the stable $\mathrm{Ni}_{3} \mathrm{P}$ (P content between 15 and 25 at\%). ${ }^{20)}$ Maeda found that higher Ni-P compounds such as $\mathrm{Ni}_{5} \mathrm{P}_{4}$ and $\mathrm{Ni}_{7} \mathrm{P}_{3}$, in addition to $\mathrm{Ni}_{3} \mathrm{P}$, exist in the films containing less than $12 \mathrm{at} \% .^{21)}$ This also 


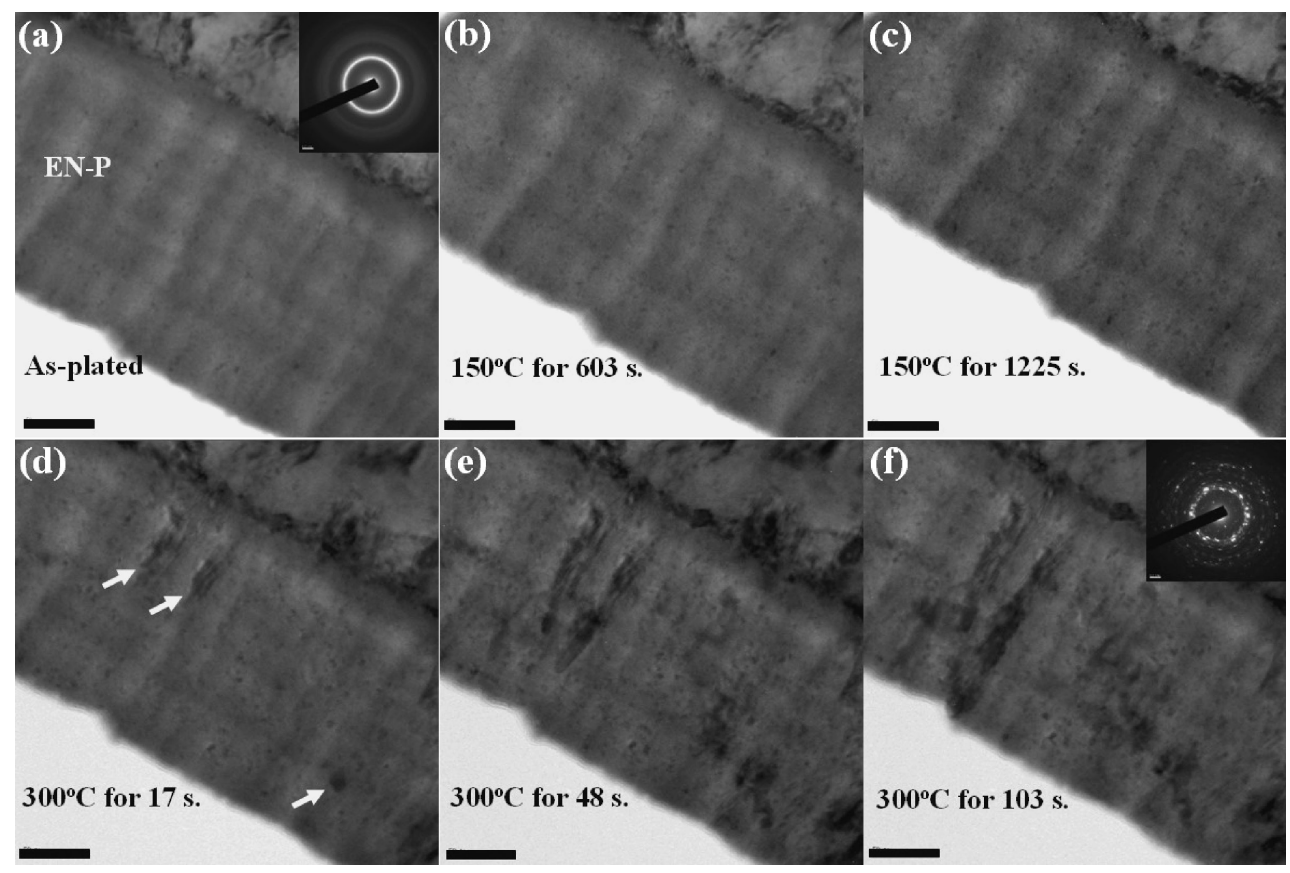

Fig. 5 In-situ TEM images taken from the step heat treatment $\left(150^{\circ} \mathrm{C}\right.$ followed by $\left.300^{\circ} \mathrm{C}\right)$ : (a) as-plated EN-P, (b) (c) at $150^{\circ} \mathrm{C}$, and (d) (f) at $300^{\circ} \mathrm{C}$. The scale bar shown in TEM images is $50 \mathrm{~nm}$.

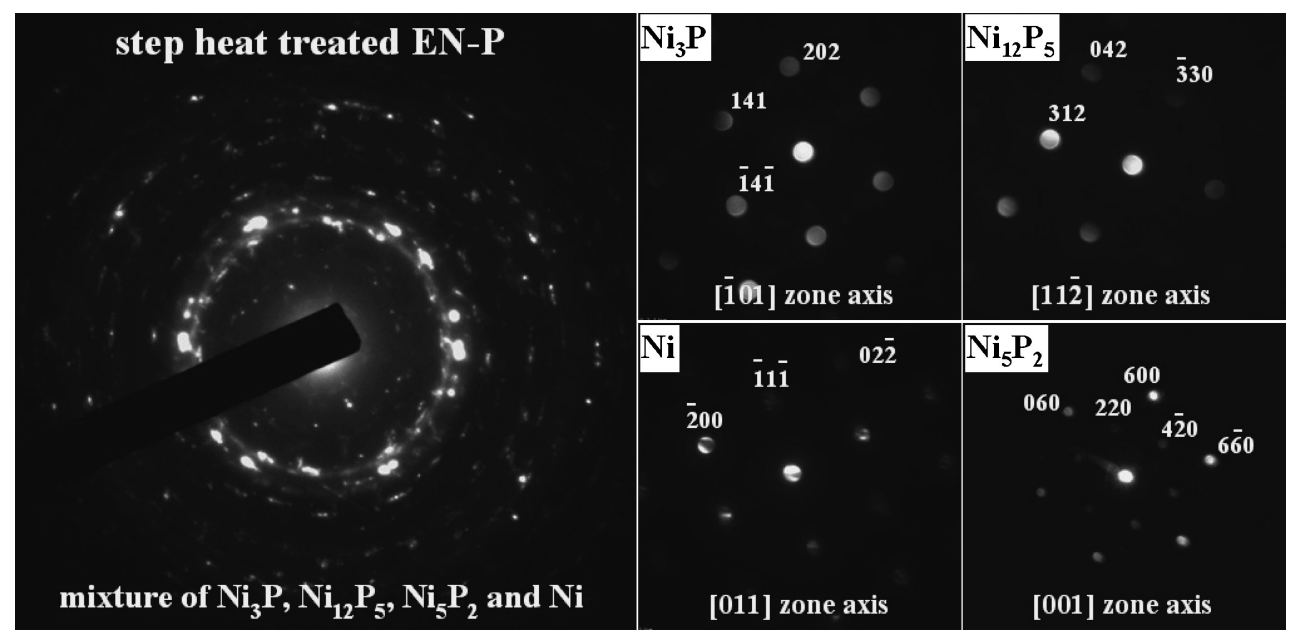

Fig. 6 NBED analyses on the step heat treated EN-P UBM shown in Fig. 5(f). The crystallized EN-P UBM was a mixture of Ni ${ }_{3} \mathrm{P}, \mathrm{Ni}_{12} \mathrm{P}_{5}$, $\mathrm{Ni}_{5} \mathrm{P}_{2}$ and $\mathrm{Ni}$.

confirmed that various Ni-P compounds formed in the EN-P UBM with a medium phosphorous content (15 at\%) are due primarily to a step heat treatment. And these results are the systematically work presenting the crystallization process of high $\mathrm{P}$ compound in the films containing medium $\mathrm{P}$ (15 at\%).

\subsection{Crystallization behaviors of the EN-P with the medium phosphorous}

Many studies reported the crystallization behavior of medium P containing EN-P films..$^{6,12,13,16,17)}$ They claimed that a heat treated EN-P film with a medium $\mathrm{P}$ consists of crystallized $\mathrm{Ni}$ and $\mathrm{Ni}_{3} \mathrm{P}$. Figure 7 shows a schematic diagram of the crystallization behavior of EN-P with 15 at $\%$ phosphorous. Heat treatment enhanced structural relaxation of the as-plated EN-P film. The rate of Ni diffusion was relatively faster than that of phosphorous. Therefore, the size of the Ni-Ni clusters increased during heat treatment, such that the precipitation of nanocrystalline Ni in the EN-P film develops (Fig. 7(a) $\rightarrow$ (b)). At higher temperatures, a stable microstructure of a mixture of $\mathrm{Ni}_{3} \mathrm{P}$ and $\mathrm{Ni}$ can be formed as a result of recrystallization (Fig. $7\left(\right.$ b) $\rightarrow$ (c)), ${ }^{13,16,18)}$ which agrees with the results taken from a single heat treatment (see Fig. 2(b)). As shown in previous TEM analyses in Figs. 3 and 4, the size of the Ni-Ni cluster continues to grow in an intermediate temperature of the step heat profile. ${ }^{22)}$ At the region between the Ni rich area with a phosphorous concentration of $\sim 23$ at $\%$, the crystallization behavior is similar to that of EN-P with a high phosphorous content $(>20$ at $\%)$. In addition to $\mathrm{Ni}_{3} \mathrm{P}$ and $\mathrm{Ni}$, other Ni-P compounds formed, such as $\mathrm{Ni}_{12} \mathrm{P}_{5}$ and $\mathrm{Ni}_{5} \mathrm{P}_{2}$, resulting from a step heat treatment. Therefore, the crystallization process of EN-P with a medium phosphorous content induced by the 


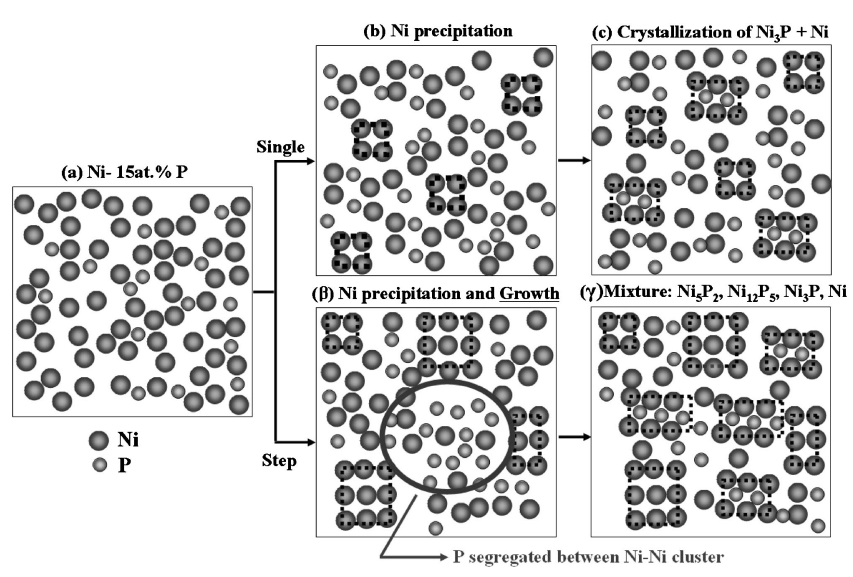

Fig. 7 Schematic diagram of crystallization behaviors of the EN-P with the medium phosphorous (15 at\%).

step heat profile can be described as follows: structural relaxation $\rightarrow \mathrm{Ni}$ precipitation $\rightarrow$ phosphorous segregation between a $\mathrm{Ni}-\mathrm{Ni}$ cluster at an intermediate temperature (Fig. $7(\mathrm{a}) \rightarrow(\beta)) \rightarrow$ mixture of $\mathrm{Ni}_{5} \mathrm{P}_{2}, \mathrm{Ni}_{12} \mathrm{P}_{5}, \mathrm{Ni}_{3} \mathrm{P}$ and $\mathrm{Ni}$ (Fig. $7(\beta) \rightarrow(\gamma)$ ). Again, a step heat treatment of the EN-P with a medium phosphorous content contributes to the formation of a range of Ni-P compounds.

\section{Conclusions}

XRD and in-situ TEM were used to examine the effects of different heat profiles on the crystallization behavior of EN-P UBM with a medium phosphorous content. A single heat treatment of the EN-P UBM at $300^{\circ} \mathrm{C} / 60$ min yielded $\mathrm{Ni}$ and $\mathrm{Ni}_{3} \mathrm{P}$ as the primary precipitates. The step heat profile of $150^{\circ} \mathrm{C} / 60 \mathrm{~min}$ followed by $300^{\circ} \mathrm{C} / 60 \mathrm{~min}$ enabled the growth of more complex crystalline Ni-P compounds in the formation of $\mathrm{Ni}_{3} \mathrm{P}, \mathrm{Ni}_{12} \mathrm{P}_{5}, \mathrm{Ni}_{5} \mathrm{P}_{2}$ and $\mathrm{Ni}$. Different heat treatment processes can affect the crystallization behavior of electroless Ni-P UBM.

\section{Acknowledgments}

The authors would like to thank for financial supports from the Korea Science and Engineering Foundation (KOSEF) grant funded by the Korea government (MEST, No. 20090060183) and Brain Korea 21 program.

\section{REFERENCES}

1) J. Simon, E. Zakel and H. Reich: Proc. 40th Electronic Components and Technology Conference, (New York, 1990) pp. 412.

2) K. Zeng and K. N. Tu: Mater. Sci. Eng. R. 38 (2002) 55.

3) J. W. Yoon and S. B. Jung: Surf. Coat. Tech. 200 (2006) 4440.

4) H. B. Kang, J. W. Lee, J. H. Bae, M. H. Park, J. W. Yoon, S. B. Jung, J. S. Ju and C. W. Yang: J. Mater. Res. 23 (2008) 2195.

5) H. B. Kang, J. H. Bae, J. W. Lee, M. H. Park, J. W. Yoon, S. B. Jung and C. W. Yang: J. Electron. Mater. 37 (2008) 84.

6) J. W. Yoon, H. S. Chun, H. B. Kang, M. H. Park, C. W. Yang, H. J. Lee and S. B. Jung: Surf. Rev. Lett. 14 (2007) 827.

7) A. H. Graham, R. W. Lindsay and H. J. Read: J. Electrochem. Soc. 112 (1965) 401.

8) N. M. Martyak: Chem. Mater. 6 (1994) 1667.

9) P. S. Kumar and P. K. Nair: J. Mater. Process. Technol. 56 (1996) 511.

10) M. H. Staia, E. S. Puchi, G. Castro, F. O. Ramirez and D. B. Lewis: Thin Solid Film 355 (1999) 472.

11) H. Pfeiffer, F. Tancret and T. Brousse: Mater. Chem. Phys. 92 (2005) 534.

12) E. Ma, S. Luo and P. Li: Thin Solid Film 166 (1988) 273.

13) K. Hur, J. Jeong and D. Lee: J. Mater. Sci. 25 (1990) 2573.

14) G. W. Marshall, D. B. Lewis and B. E. Dodds: Surf. Coat. Technol. 53 (1992) 223.

15) D. Tachev, J. Georgieva and S. Armyanov: Electrochim. Acta 47 (2001) 359.

16) J. Gao, Y. Wu, L. Liu, B. Shen and W. Hu: Mater. Lett. 59 (2005) 1665.

17) TH. Hentschel, D. Isheimi, R. Kirchheimi, F. Mueller and H. Kreye: Acta Mater. 48 (2000) 933.

18) H. S. Yu, S. F. Luo and Y. R. Wang: Surf. Coat. Technol. 148 (2001) 143.

19) E. Vafaei-Makhsoos: J. Appl. Physics 51 (1980) 6366.

20) U. Pittermann and S. Ripper: Z. Metallkde. 74 (1983) 783.

21) H. Maeda: Trans. National Res. Inst. Metals 12 (1970) 211.

22) H. B. Kang, J. H. Bae, J. W. Lee, M. H. Park, Y. C. Lee, J. W. Yoon, S. B. Jung and C. W. Yang: Scr. Mater. 60 (2009) 257. 